\title{
PEMBELAJARAN SIFAT-SIFAT GRAFIK FUNGSI EKSPONEN DAN LOGARITMA DENGAN SOFTWARE GEOGEBRA
}

\author{
Rizka Azizatul Latifah, S.Pd. \\ MAN 1 Kulon Progo, Jalan Mandung Pengasih, Kulon Progo; rizka.twin@gmail.com
}

\begin{abstract}
Abstrak. Pembelajaran matematika diharapkan dapat menumbuhkan keterampilan $4 \mathrm{c}$ (critical thinking and problem solving, communication, collaboration, dan creative and innovative). Salah satu kegiatan untuk menumbuhkan keterampilan tersebut adalah menganalisis grafik fungsi eksponen dan logaritma untuk menemukan sifat-sifatnya. Analisis grafik fungsi membutuhkan media visualisasi yang tepat untuk menggambarkan dengan jelas bentuk grafik fungsi pada koordinat kartesius agar lebih mudah dipahami dan dimengerti. Geogebra merupakan software yang dapat dimanfaatkan untuk memvisualisasikan objek matematika, termasuk grafik fungsi. Geogebra memudahkan pengguna dengan lukisan grafik yang akurat, tepat, dan cepat sehingga dapat memberi pengalaman baru kepada peserta didik dalam melihat visualisasi grafik fungsi dan menemukan sifatnya. Artikel ini membahas pembelajaran fungsi eksponen dan logaritma pada materi sifat-sifat grafik fungsi eksponen dan logaritma dengan menggunakan software Geogebra.
\end{abstract}

Kata Kunci. geogebra, fungsi eksponen, fungsi logaritma.

\section{Teaching Characteristics of Graphs of Exponential and Logarithmic Function Using Geogebra}

\begin{abstract}
Learning mathematics is expected to grow up $21^{\text {st }}$ century skills called the $4 \mathrm{C}$ 's (critical thinking and problem solving, communication, collaboration, dan creative and innovative). One of activity to grow up that skills is graph analysis. Characteristics of graph of exponential and logarithmic function is one of topics wich need an analysis. To analysis a graphs, students need a right media. Geogebra is a software that can visualize mathematics object including graphic function. This paper will discuss how teaching characteristics of graphs of eksponential and logarithmic function using Geogebra.
\end{abstract}

Keyword. Geogebra, exponential function, logarithmic function.

\section{Pendahuluan}

Dinamika atau perubahan yang terjadi di abad ke-21 sangatlah cepat sehingga diperlukan fleksibilitas dan adabtasi yang baik untuk mampu bertahan dan mengikuti perkembangan zaman. Menurut Redhana (2019: 2239) abad ke-21 merupakan abad pengetahun, abad ekonomi, abad teknologi informasi, globalisasi, revolusi industi 4.0, dan lain sebagainya. Oleh karena itu diperlukan keterampilan tersendiri untuk mengantisipasi dan beradaptasi terhadap perubahan tersebut. Keterampilan tersebut adalah critical thinking and problem solving (berpikir kritis dan pemecahan masalah), communication (komunikasi), collaboration (kolaborasi), dan creative and innovative (kreatif dan inovatif) atau dikenal dengan keterampilan 4C (Partnership for 21 ${ }^{\text {st }}$ Century Skills, 2008). Pembelajaran matematika merupakan salah satu pembelajaran yang dapat menumbuhkan keterampilan $4 \mathrm{C}$, salah satunya melalui kegiatan analisis dalam proses pembelajaran matematika. Analisis merupakan salah 
satu aktivitas utama dalam pembelajaran matematika yang dapat memfasilitasi peserta didik proses berpikir kritis dan pemecahan masalah, komunikasi, kolaborasi, kreatif dan inovatif.

Matematika sering kali dianggap pelajaran yang sulit oleh kebanyakan peserta didik. Materi yang kompleks membuat peserta didik merasa kesulitan. Terlebih kegiatan analisis memerlukan tingkat pemahaman yang cukup tinggi. Oleh karena itu, dalam proses menganalisis dan mengkonstruk suatu pengetahuan baru, media pembelajaran memiliki peran yang penting untuk memberikan visualisasi maupun kondisi yang lebih nyata agar lebih mudah dimengerti dan dipelajari peserta didik. Materi sifat-sifat fungsi eksponen dan logaritma merupakan materi yang membutuhkan visualisasi grafik sehingga dapat memudahkan peserta didik dalam menganalisisnya. Salah satu program komputer atau software yang dapat dimanfaatkan untuk memvisualisakan grafik fungsi eksponen dan logaritma adalah Geogebra.

Berdasarkan hal tersebut, penulis tertarik untuk membuat artikel dengan judul Pembelajaran Fungsi Eksponen dan Logaritma pada Materi Sifat-Sifat Grafik Fungsi Eksonen dan Logaritma dengan Software Geogebra. Artikel ini secara khusus akan membahas bagaimana pembelajaran fungsi eksponen dan logaritma khususnya pada materi sifat-sifat grafik fungsi eksponen dan fungsi logaritma dengan menggunakan software Geogebra serta keterkaitannya dengan pengembangan keterampilan $4 \mathrm{C}$ peserta didik.

\section{Pembahasan}

\subsection{Geogebra}

Menurut Susilana (2016) media pembelajaran merupakan segala jenis atau bentuk benda yang dapat dimanipulasi, dilihat, didengar, dibaca dan dibicarakan beserta instrumen yang digunakan pada kegiatan tersebut. Media pembelajaran yang digunakan akan berpengaruh terhadap keberhasilan suatu pembelajaran. Pembelajaran dapat ditunjang dengan penggunaan teknologi komputer serta software atau aplikasi di dalamnya. Kegiatan pembelajaran dengan melibatkan kehadiran teknologi juga dapat meningkatkan kemampuan bepikir peserta didik. Beberapa penelitian menunjukkan bahwa kehadiran teknologi komputer dapat digunakan untuk mengembangkan kemampuan berpikir tingkat tinggi dan analisis (Nayak, 2016).

Geogebra merupakan salah satu aplikasi/software yang dapat mendukung kegiatan pembelajaran matematika. Isman (2016:13) menyebutkan bahwa dalam pembelajaran matematika, Geogebra dapat dimanfaatkan sebagai berikut: 1) media demonstrasi dan visualisasi, 2) alat bantu konstruksi pengetahuan, 3) alat bantu menemukan konsep, dan 4) menyiapkan bahan-bahan pengajaran. Program tersebut juga dapat digunakan untuk meningkatkan pemahaman peserta didik terhadap konsep yang telah dipelajari maupun sebagai media untuk mengenalkan atau mengkonstruksi konsep baru (Fitriasari, 2016).

Geogebra merupakan aplikasi pembelajaran matematika yang dikembangkan oleh Markus Hohenwarter dkk pada tahun 2008. Aplikasi ini memiliki beberapa kelebihan diantaranya sebagai berikut.

1) Dapat diunduh secara gratis dan memiliki ukuran file yang relatif kecil (Aminah, 2016:153).

2) Dapat mengakomodasi pembelajaran matematika secara analitik, visual, dan numerik (Andri, dkk., 2018:13). 
3) Menyediakan fitur yang dapat digunakan untuk mengkonstruksi konsep matematika (Mahmudi, 2010).

4) Dapat memvisualisasikan grafik fungsi secara jelas. Dalam hal ini, objek-objek geometri yang abstrak dapat divisualisasi dan dimanipulasi secara cepat, akurat, dan efisien (Mahmudi, 2010).

\subsection{Fungsi Eksponen dan Logaritma}

Salah satu materi pokok pembelajaran matematika peminatan adalah fungsi eksponen dan logaritma. Dalam topik tersebut, terdapat materi sifat-sifat grafik fungsi eksponen dan logaritma. Berikut ini merupakan sifat-sifat grafik fungsi eksponen dan logaritma yang dipelajari peserta didik (Sukino, 2016).

Tabel 1. Sifat-Sifat Grafik Fungsi Eksponen

\begin{tabular}{|c|l|l|}
\hline No. & \multicolumn{1}{|c|}{$\begin{array}{c}\text { Bilangan pokok lebih besar dari } 1 \\
\left(y=f(x)=a^{x} ; a>1\right.\end{array}$} & \multicolumn{1}{|c|}{$\begin{array}{c}\text { Bilangan pokok antara } 0 \text { dan } 1 \\
\left(y=f(x)=a^{x} ; 0<a<1\right.\end{array}$} \\
\hline 1 & $\begin{array}{l}\text { Definit positif (kurva terletak di atas } \\
\text { sumbu-X) }\end{array}$ & $\begin{array}{l}\text { Definit positif (kurva terletak di atas } \\
\text { sumbu-X) }\end{array}$ \\
\hline 2 & Memotong sumbu $Y$ di titik $(0,1)$ & Memotong sumbu $Y$ di titik $(0,1)$ \\
\hline 3 & Memiliki asimtot datar yaitu sumbu $X$ & Memiliki asimtot datar yaitu sumbu $X$ \\
\hline 4 & Monoton naik & Monoton turun \\
\hline
\end{tabular}

Tabel 1 menunjukkan bahwa terdapat empat sifat grafik fungsi eksponen, baik yang bilangan pokoknya lebih dari satu maupun yang bilangan pokoknya antara nol dan satu. Dari kedua grafik fungsi eksponen tersebut terdapat tiga kesamaan sifat dan hanya ada satu sifat yang membedakan. Tiga kesamaan sifat tersebut yang pertama adalah definit positif yang berarti kurva dari grafik fungsi eksponen selalu berada di atas sumbu $X$. Persamaan sifat yang kedua adalah kurva grafik fungsi eksponen selalu memotong sumbu $Y$ di titik $(0,1)$ atau dengan kata lain kurvanya selalu melewati titik $(0,1)$. Ketiga, persamaan dari keduanya adalah memiliki asimtot datar yakni sumbu $X$, artinya grafik fungsi eksponen tidak pernah memotong sumbu $X$ atau selalu mendekati sumbu $X$. Akan tetapi, sifat yang membedakan yakni kemonotonan fungsinya. Grafik fungsi eksponen dengan bilangan pokok lebih dari satu selalu monoton naik atau dapat disebutkan jika $x_{1}>x_{2}$, maka $f\left(x_{1}\right)>f\left(x_{2}\right)$, sedangkan grafik fungsi eksponen dengan bilangan pokok antara nol dan satu selalu monoton turun atau dapat dikatakan $x_{1}>$ $x_{2}$, maka $f\left(x_{1}\right)>f\left(x_{2}\right)$. Agar lebih jelas terlihat perbedaan antara keduanya, berikut ini disajikan gambar grafik fungsi eksponen $y=2^{x}$ dan $y=\frac{1}{2}^{x}$. 


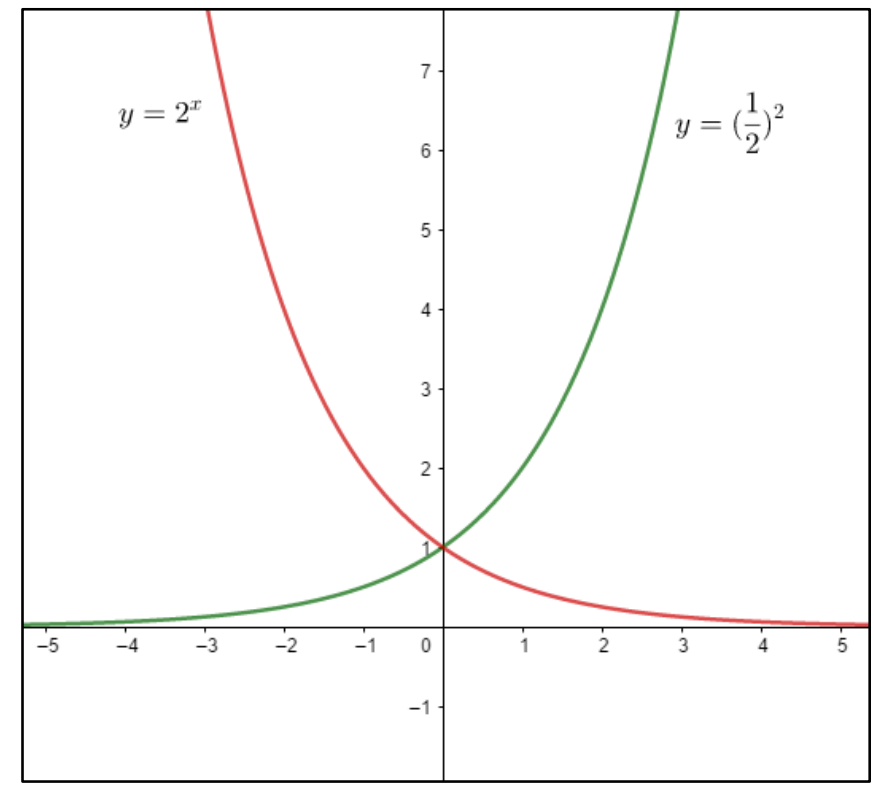

Gambar 1. Grafik fungsi eksponen $y=2^{x}$ dan $y=\frac{1}{2}^{x}$

Tabel 2. Sifat-Sifat Grafik Fungsi Logaritma

\begin{tabular}{|c|l|l|}
\hline No. & \multicolumn{1}{|c|}{$\begin{array}{c}\text { Bilangan pokok lebih besar dari } 1 \\
y=a \log x ; a>1\end{array}$} & \multicolumn{1}{c|}{$\begin{array}{c}\text { Bilangan pokok antara } 0 \text { dan } 1 \\
y=a\end{array}$} \\
\hline 1 & $\begin{array}{l}\text { Nilai } a_{\log x} \text { tidak didefinisikan untuk } \mathrm{x} ; 0<a<1 \\
\text { yang tidak positif }\end{array}$ & $\begin{array}{l}\text { Nilai } a_{\log x} \text { tidak didefinisikan untuk } \mathrm{x} \\
\text { yang tidak positif }\end{array}$ \\
\hline 2 & Memotong sumbu $X$ dititik $(1,0)$ & Memotong sumbu $X$ dititik $(1,0)$ \\
\hline 3 & $\begin{array}{l}\text { sumbu Y merupakan asimtot tegak dari } \\
\text { grafik }\end{array}$ & $\begin{array}{l}\text { sumbu Y merupakan asimtot tegak dari } \\
\text { grafik }\end{array}$ \\
\hline 4 & Fungsi $f$ monoton naik & Fungsi $f$ monoton turun \\
\hline
\end{tabular}

Tabel 2 menunjukkan terdapat empat sifat grafik fungsi logaritma, baik yang bilangan pokoknya lebih dari satu maupun yang bilangan pokoknya antara nol dan satu. Dari kedua grafik fungsi logaritma tersebut terdapat tiga kesamaan sifat dan ada satu sifat yang membedakan. Tiga kesamaan sifat tersebut yang pertama adalah nilai Nilai $a_{\log x}$ tidak didefinisikan untuk $x$ yang tidak positif, artinya fungsi logaritma selalu bernilai positif atau domainnya dari 0 sampai tak hingga dan pada grafik terlihat selalu berada di kanan sumbu $Y$. Sifat yang kedua adalah grafik fungsi logaritma selalu memotong sumbu $Y$ di titik $(1,0)$. Sifat yang ketiga adalah sumbu $Y$ merupakan asimtot dari grafik fungsi logaritma, artinya grafik fungsi logaritma tidak pernah berpotongan dengan sumbu $Y$. Akan tetapi, sifat yang membedakan yakni kemonotonan fungsinya. Grafik fungsi logaritma dengan bilangan pokok lebih dari satu selalu monoton naik atau dapat disebutkan jika $x_{1}>x_{2}$, maka $f\left(x_{1}\right)>f\left(x_{2}\right)$, sedangkan grafik fungsi logaritma dengan bilangan pokok antara nol dan satu selalu monoton turun atau dapat dikatakan $x_{1}>x_{2}$, maka $f\left(x_{1}\right)>f\left(x_{2}\right)$. Agar lebih jelas terlihat perbedaan antara keduanya, berikut ini disajikan gambar grafik fungsi logaritma $y={ }^{2} \log x$ dan $y=$ $\frac{1}{2} \log x$. 


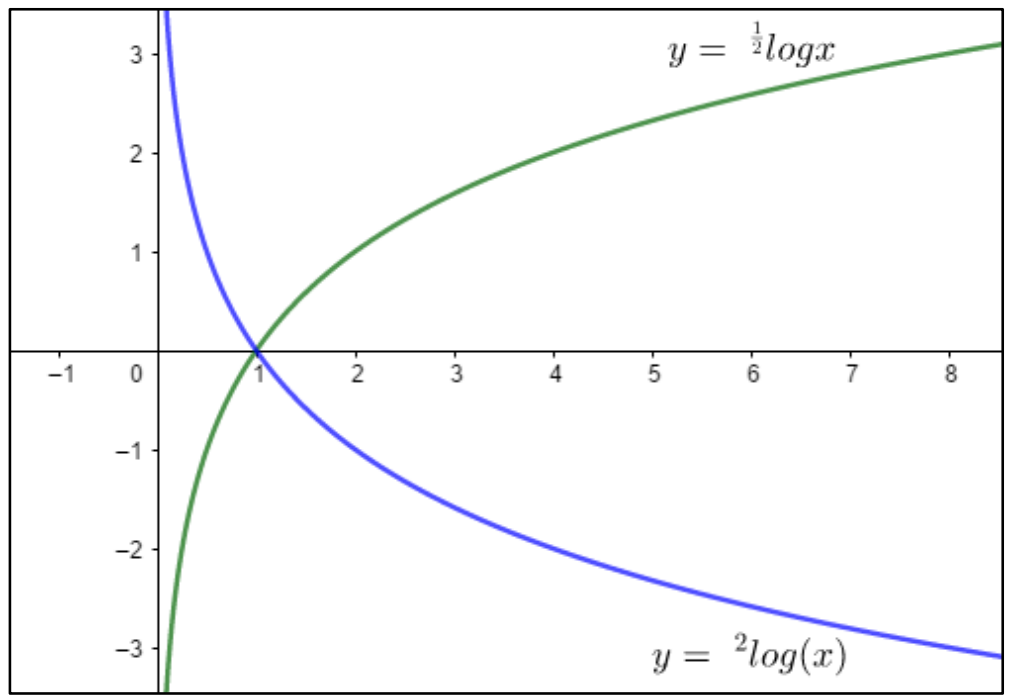

Gambar 2. Grafik fungsi logaritma $y={ }^{2} \log x$ dan $y=\frac{1}{2} \log x$

Pada pembelajaran ini, peserta didik dapat diajak untuk mencari tahu sifat-sifat grafik fungsi eksponen dan logaritma dengan menganalisis grafik fungsi eksponen dan logaritma. Kegiatan analisis grafik ini akan membuat peserta didik kebingungan jika tidak ada visualisasi grafik yang baik dan jelas. Oleh karena itu, menjadi hal yang berbeda jika analisis grafik dilakukan dengan menggunakan bantuan media pembelajaran maupun software komputer yang dapat dengan jelas menggambarkan grafik yang dimaksud. Menurut Isman (2016:11) media pembelajaran dapat memberikan pengalaman visual kepada peserta didik dalam berinteraksi dengan objek matematika yang bersifat abstrak sehingga proses penerimaan peserta didik terhadap pelajaran akan lebih berkesan. Lebih lanjut Isman (2016:12) menuturkan bahwa Geogebra merupakan software matematika yang dapat digunakan sebagai alat bantu dalam pembelajaran matematika yang salah satu fungsinya sebagai media pembelajaran matematika. Geogebra merupakan program yang efektif untuk membantu memvisualisasikan objek-objek matematika khususnya pada materi fungsi dan grafik (Isman, 2016:18). Dengan menggunakan Geogebra, peserta didik dapat melihat perubahan-perubahan yang terjadi pada grafik fungsi eksponen dan logaritma yang disajikan dan dapat menganalisis sehingga pada akhirnya akan lebih mudah menarik simpulan terkait sifat-sifat grafik fungsi tersebut.

Dalam menganalisis sifat-sifat grafik fungsi eksponen, peserta didik perlu diberikan ilustrasi beberapa grafik fungsi yang dibedakan berdasarkan perbedaan nilai-nilai bilangan pokoknya. Terdapat dua jenis fungsi eksponen yang akan dibahas yakni fungsi eksponen dengan bilangan pokok lebih besar dari satu $\left(y=f(x)=a^{x} ; a>1\right)$ dan fungsi eksponen dengan bilangan pokok antara nol dan $1\left(y=f(x)=a^{x} ; 0<a<1\right)$. Fungsi-fungsi tersebut kemudian akan diilustrasikan dalam software Geogebra.

\section{a. Grafik fungsi eksponen $y=f(x)=a^{x} ; a>1$}

Dalam pembelajaran grafik fungsi eksponen ini, peserta didik difasilitasi dengan menggunakan LKPD (Lembar Kerja Peserta Didik). LKPD ini memuat tahapan-tahapan pembelajaran yang akan dilaksanakan peserta didik dalam menganalisis sifat-sifat grafik fungsi eksponen serta memfasilitasi peserta didik dalam mengembangkan keterampilan 4C. Berikut ini akan disajikan tahapan pembelajaran yang dilaksanakan. 
Pertama, pembelajaran dapat dimulai dengan kegiatan tanya jawab. Guru dapat memulai dengan meminta peserta didik untuk menyebutkan contoh fungsi eksponen $f(x)=a^{x} ; a>1$ dan $f(x)=a^{x} ; 0<a<1$. Keterampilan yang dapat ditingkatkan pada tahap ini adalah keterampilan komunikasi (communication). Hal ini terkait dengan bagaimana peserta didik menyampaikan pendapat atau tanggapannya (Ibnu, 2016). Selanjutnya peserta didik dapat menuliskan contoh-contoh yang telah mereka sampaikan pada LKPD.

Kedua, peserta didik diminta untuk menginput fungsi-fungsi yang telah dituliskan ke dalam Geogebra. Berikut ini adalah contoh fungsi eksponen yang akan diinput $f(x)=2^{x}, g(x)=$ $3^{x}, h(x)=4^{x}, p(x)=5^{x}$ dan $f(x)=\left(\frac{1}{2}\right)^{x}, g(x)=\left(\frac{1}{3}\right)^{x}, h(x)=\left(\frac{1}{4}\right)^{x}, p(x)=\left(\frac{1}{5}\right)^{x}$.

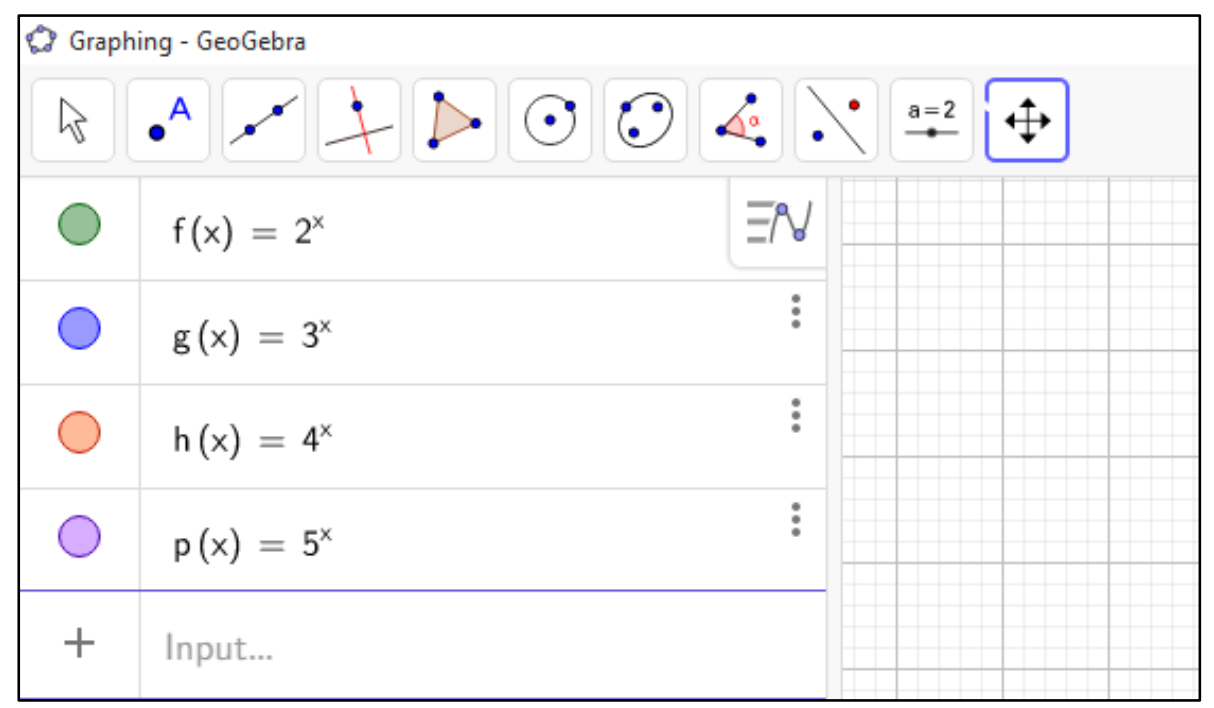

Gambar 3. Menu Input

Setelah fungsi-fungsi eksponensial diinput maka secara otomatis grafik fungsi akan terlihat di sebelah kanan pada layar. Warna pada grafik menyesuaikan warna pada menu input sehingga akan memudahkan pengguna untuk mengenali masing-masing grafik fungsi. Berikut ini adalah tampilan grafik fungsi eksponen yang terlihat.

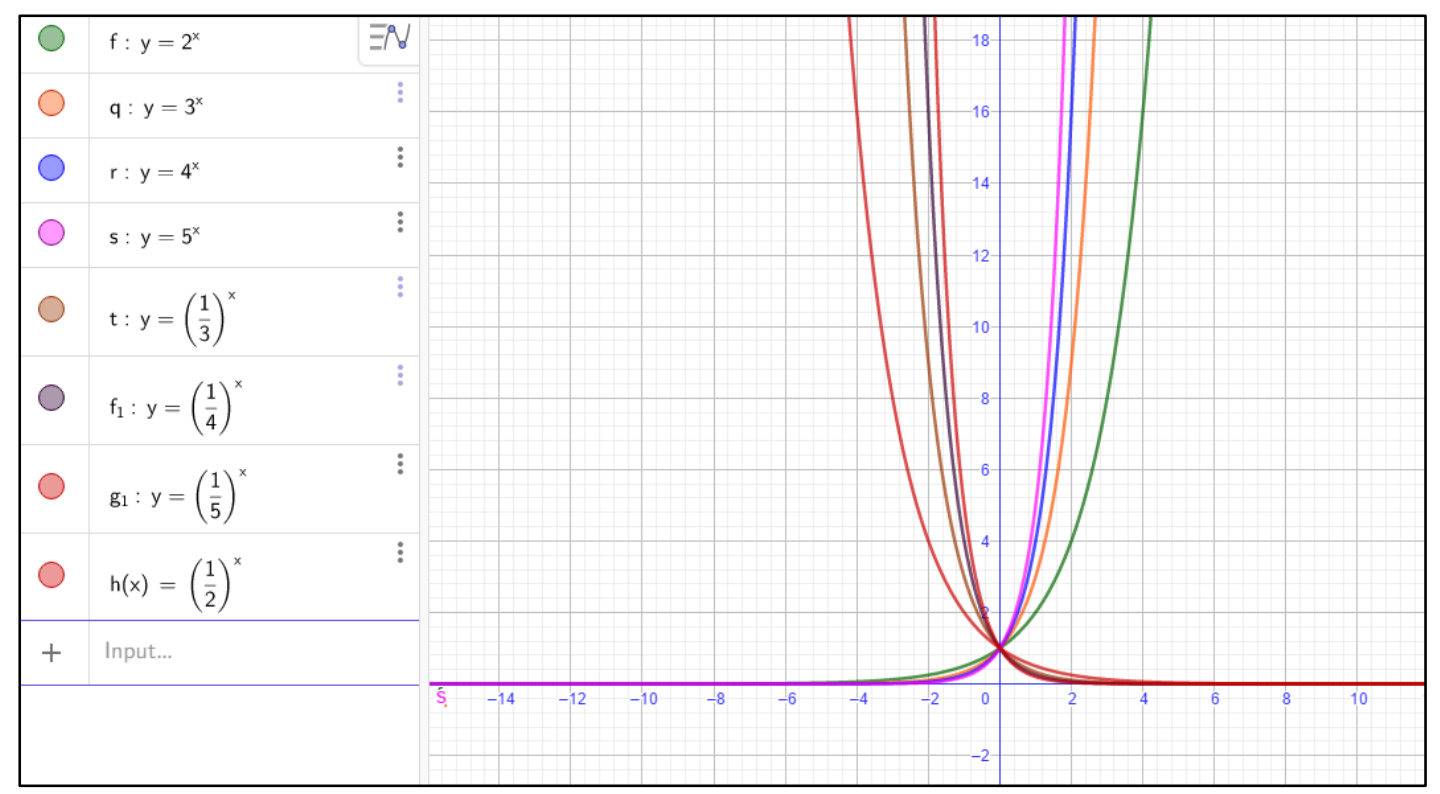

Gambar 4. Grafik Fungsi Eksponen 
Pada gambar 4 terlihat beberapa grafik fungsi eksponensial dan fungsi eksponensial (di sebelah kiri) yang telah diinput. Antara fungsi dan grafik fungsinya memiliki warna yang sama sehingga memudahkan pengguna untuk mengetahui dan mengidentifikasi setiap grafik serta menarik untuk dilihat. Dengan menggunakan Geogebra, grafik fungsi terlukis dengan jelas dan presisi sehingga pengguna akan lebih jelas dalam melakukan pengamatan dan analisis. Mahmudi (2010:471) juga menuturkan bahwa Geogebra memiliki keunggulan dalam menghasilan lukisan-lukisan yang cepat dan teliti dibandingkan dengan menggunakan pensing, jangka, dan penggaris. Pada tahap ini keterampilan yang dikembangkan yaitu keterampilan berpikir kreatif (creative thinking).

Ketiga, melihat dan membandingkan persamaan maupun perbedaan antara grafik fungsi eksponensial yang bilangan pokoknya lebih dari $1(a>1)$ dan yang bilangan pokoknya antara nol dan $1(0<a<1)$. Dalam hal ini, peserta didik akan menganalisis grafik fungsi eksponen sehingga dapat menemukan sifat-sifat grafik fungsinya. Pada tahap ini, keterampilan yang dikembangkan yakni keterampilan berpikir kreatif (creative thinking) dan berpikir kritis (critical thinking). Hal ini dikarenakan peserta didik diminta untuk membandingkan, melihat persamaan dan perbedaan, dan akhirnya menemukan sifat grafik.

Saat mengamati grafik, peserta didik perlu diberikan stimulus berupa pertanyaan-pertanyaan yang dapat mengarahkan pada simpulan mengenai sifat-sifat grafik fungsi eksponen tersebut. Berikut ini adalah contoh pertanyaan yang dapat diberikan:

- Bagaimanakah letak grafik fungsi eksponensial tersebut?

Pertanyaan ini akan mengerucutkan perhatian peserta didik pada letak grafik fungsi. Seluruh grafik fungsi eksponen terletak di atas sumbu $X$. Harapannya peserta didik akan menemukan bahwa grafik fungsi eksponen memiliki sifat definit positif atau kurva berada di atas sumbu $X$.

- Apakah grafik fungsi eksponen memotong sumbu Y?

Pertanyaan ini akan menuntun peserta didik untuk melihat perpotongan grafik. Harapannya peserta didik akan menemukan sifat grafik fungsi eksponen yakni selalu memotong sumbu $Y$ di titik $(0,1)$.

- Apakah grafik fungsi eksponen memotong sumbu X?

Pertanyaan ini akan mengarahkan peserta didik dalam melihat asimtot. Untuk melihat secara lebih detail, peserta didik dapat memperbesar tampilan grafik sehingga akan nampak jelas bahwa grafik tidak menyentuh sumbu $X$ dan hanya mendekati saja. Dari pertanyaan ini diharapkan akan dapat menemukan sifat grafik fungsi eksponen yang berikutnya yaitu memiliki asimtot datar yakni sumbu $X$.

- Bagaimanakah kemonotonan grafik tersebut?

Pertanyaan ini akan membimbing peserta didik dalam menentukan perbedaan sifat grafik fungsi eksponen dengan bilangan pokok lebih dari 1 dengan grafik fungsi eksponen dengan bilangan pokok antara nol dan satu. Dengan melihat perbedaan kemonotongan antara keduanya, peserta didik diharapkan akan menemukan bahwa untuk $y=a^{x} ; a>1$ memiliki kurva yang monoton naik atau fungsi selalu naik. Sedangkan untuk $y=a^{x} ; 0<$ $a<1$ memiliki kurva yang monoton turun atau fungsi selalu turun.

Keempat, setelah proses menemukan sifat-sifat fungsi eksponen selesai maka kegiatan selanjutnya yakni presentasi dan diskusi terkait penemuan sifat-sifat grafik fungsi logaritma. Kegiatan ini dapat dilakukan untuk kegiatan klasikal di kelas. Di akhir kegiatan, peserta didik 
juga diminta untuk menentukan perbedaan dan persamaan dari grafik fungsi eksponen serta simpulan yang diperoleh. Pada tahap ini, keterampilan yang dikembangkan yakni keterampilan berkomunikasi (communication) karena peserta didik diberikan kesempatan untuk menyampaikan hasil penemuannya di hadapan peserta didik yang lain dan juga keterampilan berkolaborasi (collaboration), pada kegiatan ini ada kerjasama yang dilakukan untuk bersama-sama merumuskan simpulan.

\section{b. Grafik Fungsi Logaritma}

Ditinjau dari bilangan pokoknya, grafik fungsi logaritma $f(x)=y={ }^{a} \log x$ dapat dikelompokan menjadi 2 macam yaitu: grafik fungsi logaritma dengan bilangan pokok $a>1$ dan grafik fungsi logaritma dengan bilangan pokok $0<a<1$. Pada pembelajaran sifat-sifat grafik fungsi logaritma ini, peserta didik dapat difasilitasi dengan LKPD dan Geogebra sehingga peserta didik dapat menemukan sifat-sifat fungsi logaritma melalui pengamatan dan analisis. Berikut ini adalah tahapan-tahapan pembelajaran yang dilaksanakan.

Pertama, seperti pada fungsi eksponen, guru dapat memulai dengan bertanya kepada peserta didik mengenai contoh fungsi logaritma. Lebih lanjut, peserta didik juga dapat diminta untuk melihat keterkaitan antara eksponen dengan logaritma. Pada tahap ini keterampilan communication dikembangakan dengan kegiatan tanya jawab dan diskusi.

Kedua, langkah berikutnya yakni menginput fungsi logaritma yang telah dicontohkan oleh peserta didik dalam Geogebra. Sebagai contoh, fungsi logaritma dengan bilangan pokok $a>$ 1 yaitu

$y={ }^{2} \log x, y={ }^{3} \log x, y={ }^{4} \log x$ dan fungsi logaritma dengan bilangan pokok $0<a<1$ yakni $y=\frac{1}{2} \log x, y=\frac{1}{3} \log x, y=\frac{1}{4} \log x$. berikut ini adalah tampilan grafik fungsi logaritma yang terlihat pada Geogebra.

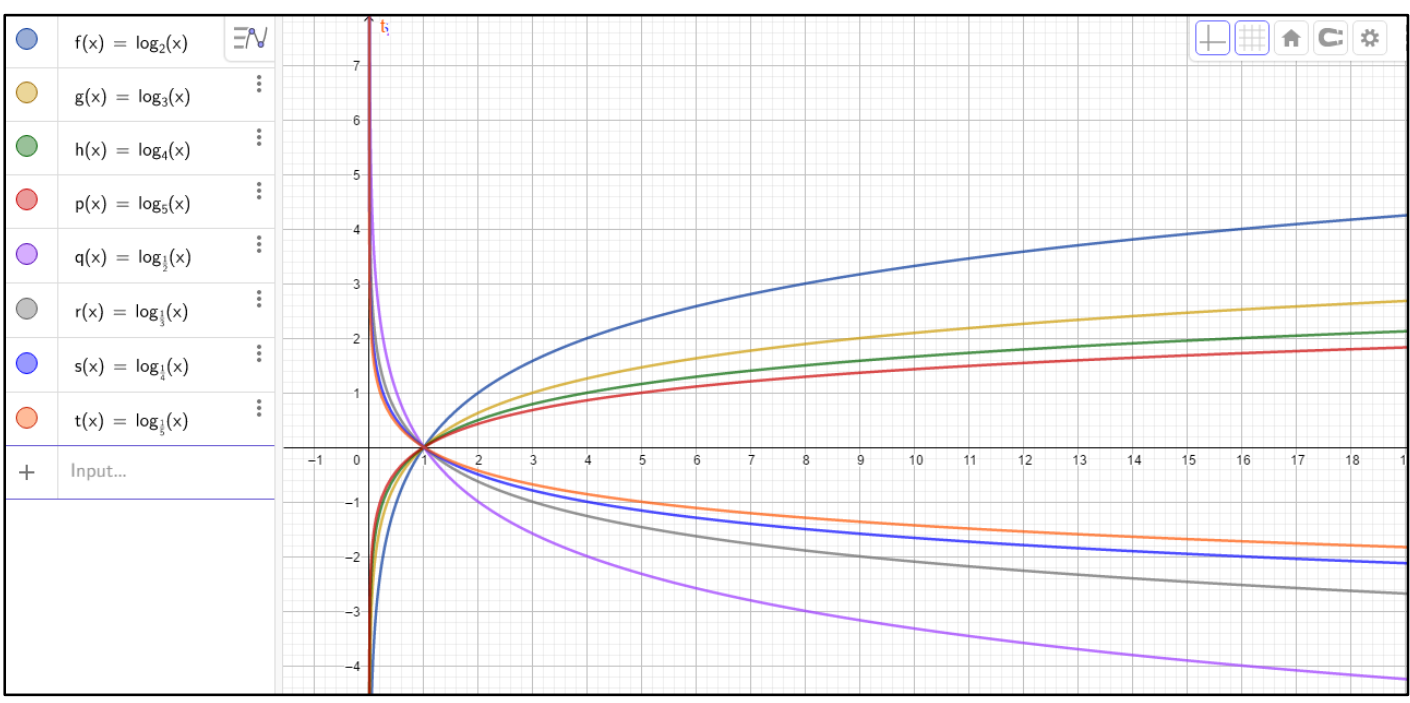

Gambar 5. Grafik Fungsi Logaritma

Ketiga, melihat dan membandingkan persamaan dan perbedaan antara grafik fungsi logaritma yang bilangan pokoknya lebih dari $1(a>1)$ dan yang bilangan pokoknya antara nol dan 1 $(0<a<1)$ dengan melihat grafik fungsi logaritma yang disajikan oleh Geogebra. Dalam 
proses eksplorasi sifat grafik fungsi logaritma, peserta didik dapat diberikan stimulus berupa pertanyaan-pertanyaan yang dapat mengarahkan pada penemuan sifat-sifat grafik fungsi logaritma tersebut. Berikut ini adalah contoh pertanyaan yang dapat diberikan:

- Bagaimanakah letak grafik fungsi logaritma?

Pertanyaan ini diarahkan untuk melihat posisi dari grafik fungsi logaritma. Peserta didik dapat melihat bahwa grafik fungsinya selalu berada di kanan sumbu $Y$ atau $a_{\log x}$ tidak didefinisikan untuk $x$ yang tidak positif, atau dengan kata lain nilai logaritma selalu positif. Jika dilihat dari rangenya, maka range grafik fungsi logaritma yakni antara nol sampai tak hingga.

- Apakah grafik fungsi logaritma memotong sumbu X?

Pertanyaan ini akan membimbing peserta didik untuk melihat titik yang selalu berpotongan dengan grafik fungsi logaritma yakni $(0,1)$.

- Apakah grafik fungsi logaritma memotong sumbu Y?

Pertanyaan ini akan mengarahkan peserta didik dalam melihat asimtot. Untuk melihat ada atau tidaknya perpotongan secara lebih detail, peserta didik dapat memperbesar tampilan grafik sehingga akan nampak jelas dan hanya mendekati saja. Dari pertanyaan ini diharapkan akan dapat menemukan sifat grafik fungsi logaritma yang berikutnya.

- Bagaimanakah kemonotonan grafik tersebut?

Pertanyaan ini akan membimbing peserta didik dalam menentukan perbedaan sifat grafik fungsi logaritma dengan bilangan pokok lebih dari 1 dengan grafik fungsi eksponen dengan bilangan pokok antara nol dan satu. Dengan melihat perbedaan kemonotongan antara keduanya, peserta didik diharapkan akan menemukan bahwa untuk $y=a^{x} ; a>1$ memiliki kurva yang monoton naik atau fungsi selalu naik. Sedangkan untuk $y=a^{x} ; 0<$ $a<1$ memiliki kurva yang monoton turun atau fungsi selalu turun.

- Bagaimanakah kemonotonan fungsi logaritma?

Pertanyaan ini akan membimbing peserta didik dalam menentukan perbedaan sifat grafik fungsi logaritma dengan bilangan pokok lebih dari 1 dengan grafik fungsi eksponen dengan bilangan pokok antara nol dan satu.

Keempat, kegiatan terakhir yakni presentasi dan diskusi terkait penemuan sifat-sifat grafik fungsi logaritma. Di akhir kegiatan, peserta didik juga diminta untuk menentukan perbedaan dan persamaan dari grafik fungsi logaritma serta simpulan yang diperoleh. Tahap ini mengembangkan keterampilan berkomunikasi (communication) karena peserta didik diberikan kesempatan untuk menyampaikan hasil kerjanya di hadapan peserta didik yang lain.

Pembelajaran grafik fungsi dengan menggunakan Geogebra sangatlah menarik. Grafik fungsi yang disajikan terlihat presisi, bagus dan berwarna warni sehingga menambah daya tarik peserta didik dalam belajar. Selain itu melukis grafik fungsi menggunakan Geogebra sangat praktis dan mudah dilakukan sehingga sangat cocok sebagai media pembelajaran. Kemudahan melukis grafik fungsi dan kelebihan grafik fungsi yang dihasilkan dengan geogebra memudahkan peserta didik dalam menganalisis grafik fungsi eksponen dan logaritma. Kejelasan grafik yang dihasilkan mempermudah peserta didik dalam mengidentifikasi sifatsifat grafik yang dihasilkan. Hal ini tentu membantu peserta didik dapat mempelajari sifatsifat grafik fungsi. Geogebra memberikan solusi kesulitan menggambar grafik fungsi yang 
mudah, presisi dan menarik yang disinyalir menyebabkan kesulitan siswa dalam memahami grafik fungsi eksponen dan logaritma.

\section{Simpulan}

Berdasarkan uraian di atas dapat disimpulkan bahwa pembelajaran sifat-sifat fungsi eksponen dan logaritma ini lebih mudah dilaksanakan dengan menggunakan bantuan software Geogebra. Geogebra memberikan keuntungan dengan lukisan grafik yang dihasilkan akurat, tepat, dan cepat sehingga akan pemberikan pengalaman baru kepada peserta didik dalam melihat visualisasi grafik fungsi eksponen dan logaritma. Oleh karena itu, guru dapat menggunakan Geogebra dalam pembelajaran matematika khususnya pada materi fungsi. Pembelajaran analisis grafik fungsi eksponen dan logaritma dapat mendorong pengembangan keterampilan berpikir peserta didik. Pembelajaran sifat-sifat fungsi eksponen dan logaritma yang dilakukan secara cermat dan bertahap, dimulai dengan meminta peserta didik menyebutkan contoh fungsi eksponen dan logaritma, kemudian melukis grafik fungsi eksponen dan logaritma menggunakan Geogebra, dilanjutkan peserta didik melakukan pengamatan dan analisis terhadap grafik fungsi tersebut dan dilanjutkan dengan presentasi serta diskusi, dapat memfasilitasi peserta didik dalam mengembangakan keterampilan 4C seperti communication pada proses tanya jawab dan diskusi, creative thinking dan critical thinking pada saat menganalisis dan menemukan sifat-sifat fungsi, serta collaboration pada saat proses diskusi. Dengan demikian penting bagi guru dapat menggunakan Geogebra dalam pembelajaran matematika khususnya pada materi grafik dan geometri, sehingga dapat memudahkan peserta didiknya dalam belajar.

\section{Daftar Pustaka}

Fitriasari, P. 2016. Pemanfaatan Software Geogebra dalam Pembelajaran Matematika. Jurnal Dosen Universitas PGRI Palembang.

Mahmudi, A. 2010. Pemanfaatan Geogebra dalam Pembelajaran Matematika. Yogyakarta: UNY.

Nayak, P. Use of Technology in Teaching-Learning Mathematics. (online), (http://www.ncert.nic.in/pdf_files/use\%20of\%20technology\%20in\%20\%20teaching\%20learning\%20mathematics\%20-pratimanayak.pdf.), diakses 27 Juni 2016.

Nur, M. I. 2016. Pemanfaatan Program Geogebra dalam Pembelajaran Matematika. Delta-Pi: Jurnal Matematika dan Pendidikan Matematika. 5, 10 - 19.

Partnership for $21^{\text {st }}$ Century Skills. 2008. 21 ${ }^{\text {st }}$ Century Skills, Education and Competitiveness: A Resource and Policy Guide. Tuczon, AZ.

Rafi, I., Sabrina, N. \& Latifah, R.A. 2016. Prosiding dari Seminar Nasional Pendidikan Matematika Ahmad Dahlan. Penerapan Metode Pembelajaran Bamboo Dancing dalam Pembelajaran Keliling dan Luas Segiempat dan Segitiga untuk Meningkatkan Keterampilan 4C Siswa SMP Kelas VII. Hal: 99 - 104.

Redhana, I.W. 2019. Mengembangkan Keterampilan Abad Ke-21 dalam Pembelajaran Kimia. Jurnal Inovasi Pendidikan Kimia. 13, 2239 - 2253.

Susilana, R. 2016. Media Pembelajaran: Hakikat, Pengembangan, Pemanfaatan, dan Penilaian. Wacana Prima: Bandung. 